\title{
LA AUSENCIA DE DIRECCIONALIDAD POLÍTICA DEL PLAN ESTRATÉGICO NACIONAL. DE TURISMO: PENTUR
}

\author{
Manuel Hernán Izaguirre Sotomayor \\ Observatorio Turístico del Perú \\ EPTH - USMP - Lima
}

El Plan Estratégico Nacional de Turismo (PENTUR) debe ser la herramienta que instrumentalice la política nacional de turismo que el Poder Ejecutivo ha formulado para lograr el desarrollo sostenible del turismo nacional. Sin embargo, no existe en el país una política para el desarrollo del turismo nacional, menos que ésta sea una política de Estado.

A pesar de ello, existe el plan estratégico para implementarlo, considerándola como fin, en sí misma y no como instrumento o medio para conseguir un fin u objetivo; es más se le da el estatus de política turística.

Todo plan estratégico nacional se construye para operacionalizar una política de desarrollo en lo macro para alcanzar objetivos nacionales claros, precisos y medibles, formulados en el contexto de la política que un partido político implementa al ser gobierno, o de la política que todos los partidos políticos de una nación se comprometen implementar, cuando lleguen a serlo, convirtiéndola en política de Estado, al institucionalizarlo dentro de los estamentos estatales adecuados.

En otras palabras implementar en el terreno los lineamientos de la política turística del país, como lo ha hecho España al formular su política turística desde el año 1905, el mismo que ha cambiado, al cambiar la realidad; toda vez que la política se adecua a la realidad y no la realidad a la política ${ }^{1,2,3}$.

Es decir los lineamientos de política, no lo dan los técnicos, menos los consultores, sino los partidos políticos que llegan al poder, para ejecutar su plan de gobierno o continuar con los lineamientos de política turística concertada en un pacto social o político.

Por lo tanto, el papel de los técnicos, consultores o asesores, es formular el plan estratégico para alcanzar los objetivos estratégicos formulados en el corto, mediano y largo plazo por el Estado o por el gobierno de turno, en el marco de la política pública aprobada para el sector. 
Tampoco, la política nacional para el desarrollo del turismo, nace a través de una ley a propuesta del Congreso de la República, al considerarla, como tal declarativamente. No pues, es al revés. Un plan por más que sea estratégico, no dará resultado si carece de direccionalidad y no cuente con la decisión política de implementarlo.

Por lo tanto, no lograremos el desarrollo del turismo con el PENTUR, sino, el PENTUR debería permitir implementar el tipo de desarrollo turístico que se desea para el Perú4. Por lo tanto debería comenzar formulando los lineamientos de la política turística que el Estado o el gobierno de turno ha decidido implementar. Sin él todo plan será bueno en el papel, dado que nos conducirá a ninguna parte.

Al ser el turismo un sector desvinculado de una política turística, por lo tanto no estar inmerso en la política nacional de desarrollo que el gobierno propuso al electorado, explica, el poco interés mostrado por el gobierno hacia el sector, reduciéndose este interés, a su valoración como instrumento para el desarrollo sostenible del país, solo en lo declarativo, más no en las decisiones prioritarias traducidas éstas en los montos de la asignación presupuestal.

Sin la direccionalidad política y sin la adecuada asignación presupuestal seguirá el turismo creciendo vegetativamente, a pesar de contar con un "modelo turístico de éxito", como se precisa en el PENTUR.

Precisamente, una de las razones, por la que España está entre los tres primeros destinos turísticos del mundo, es al hecho de implementar la política turística española, a través de un Plan Estratégico al año 2020, con objetivos y metas claramente enunciados, factibles y medibles, así mismo, con estrategias adecuadas para lograrlo.

Lo más importante, desde mi punto de vista, es su implementación con Planes Operativos anuales, totalmente financiados, con objetivos claros $y$ cuantificables, así como planes estratégicos de marketing con objetivos cuantificables y medibles, sistemas de supervisión y monitoreo, a través de indicadores de proceso, eficiencia y de impacto.

\section{POLÍTICA TURÍSTICA Y ADMINISTRACIÓN}

La formulación e implementación de una política pública para el desarrollo del turismo, además de ser la toma de posición del Estado, frente a cuestiones socialmente problematizadas, son ámbitos separados y yuxtapuestos de reflexión y acción.

La administración no es ajena a la política. La implementación de una política pública es considerada como actividad propia del Poder Ejecutivo. Las cuestiones administrativas no son cuestiones políticas, a pesar que la política fija las tareas que la administración realizará.

La formulación de una política publica es tomar partido con el "interés general" de la sociedad, a la solución de problemas sociales. Su "implementación" tiene lugar en el ámbito de la burocracia estatal, reino de la rutina, la ineficiencia y la corrupción.

Por lo tanto en la vinculación entre la actividad de formulación y planificación de las políticas públicas y la actividad del aparato burocrático a cargo de su implementación se evidencia la bondad de la política y la naturaleza intrínseca conspirativa de la burocracia.

\section{POLÍTICA TURÍSTICA Y RACIONALIDAD TÉCNICA}

Nada mas ajeno a la política que las premisas de neutralidad valorativa, certidumbre y racionalidad sustantiva. La negociación constituye, en el intercambio, el principal mecanismo de transacción, siendo el elemento característico de la acción política que se da en el mercado, obligando a una decisión colectiva en el consenso. La coordinación entre ellos se logra solo como resultado de transacciones políticas.

Las políticas públicas responden habitualmente a cuestiones socialmente disputadas, haciendo finalmente que la razón política subordine a la razón técnica. 
Sin embargo, pareciera que en ausencia de una política pública para el desarrollo del turismo nacional, se quiere que el PENTUR, subordine la razón política, explicitando la razón del porque el turismo nacional sigue postergado.

\section{¿Es estratégico para el Perú ofertar de todo para todos los mercados turísticos existentes?}

Precisamente, la más importante decisión que debe tomar el gobierno, es sobre el tipo de producto turístico a ofertar, como país, a los mercados emisores mundiales, dado que sin él, no existe la posibilidad de ser líder en mercado turístico alguno. Imaginemos que la empresa que dirigimos fabrica calzado, por lo tanto nuestro mercado es el del calzado.

Ahora bien, tendríamos que decidir si vamos a fabricar calzados para bebés, para nin̄os, para adultos, para damas, para hombres, calzados de vestir, deportivos u ortopédicos.

Si después, de realizado el análisis de situación, se determina que nuestras fortalezas nos posibilitan mejores perspectivas de éxito en el nicho de mercado del calzado para damas, porque así aprovecharíamos mejor las oportunidades que nos da este segmento de mercado, se decide que este será nuestro nicho de mercado. Decisión que conlleva a dejar de lado los otros segmentos de mercado del calzado, por no ser nuestro negocio y no interesarnos en él, además, al hacerlo, se determinó automáticamente a nuestra competencia.

Acabamos de realizar lo que Michel Porter llama "trade off" o compensaciones que implica que para tener algo más de algo, hay que tener menos de otra cosa, dado que solo se pueden tener ganancias en un área a expensas de otra. Es decir saber, lo que no se debe hacer.

Una vez determinado el nicho de mercado a atender, se debe aprovechar todas las capacidades y ventajas comparativas y competitivas al elaborar el mejor calzado para damas que deslumbre a nuestros clientes por su calidad de producto y la calidad de servicio que se le brinda.

Finalmente, en este contexto, si nuestro mercado es el turístico y dentro de él están el turismo histórico, cultural, el de aventura, el místico o vivencial, el agroturismo, el turismo de naturaleza, el de sol y playa, el de convenciones y eventos, el corporativo, el gastronómico, el literario, el termalismo, el de salud, el de incentivos, etc.

Es obvio, que el gobierno, o el líder del partido político que gobierna el país, tiene que optar por alguno o algunos de ellos, donde nuestras ventajas comparativas y competitivas logradas aseguren por un lado, su desarrollo sostenido y por el otro lado, logren el liderazgo regional o mundial en ese nicho de mercado. No hacerlo determinará ser mediocres en todo y excelentes o buenos en ninguno.

Supongamos que se optó por posicionar al Perú como destino histórico cultural. Esto implicaría elaborar, con los mejores atractivos, el producto turístico que ofertaríamos en el nicho de mercado del turístico histórico cultural, que satisfaga la necesidad o deseo de este nicho de mercado desbordando sus expectativas, al garantizar a los turistas las condiciones y facilidades mínimas para gozar del atractivo (acceso, transporte, hospedaje y alimentación).

En seguida agregar más valor para el cliente (seguridad, guiado, calidad de servicio, información de calidad y oportuna, etc., etc.) en la búsqueda permanente de diferenciarnos de la competencia. Finalmente se tendría que preguntar constantemente a los clientes sobre la forma que les hubiera gustado recibir el servicio (encuestas pre y post servicio) para su perfeccionamiento y mejora continua de la calidad del servicio brindado al cliente. Con lo mencionado, hemos definido y elaborado el producto turístico adecuado para introducirlo en el mercado.

Además necesitamos determinar el precio del producto (segunda decisión estratégica a tomar), que canales de comercialización (plaza) utilizaremos y que mezcla promocional ejecutaremos (en la cual la promoción es una de las actividades que la componen). Al interconectar todo lo mencionado hemos elaborado la oferta turística para el nicho de mercado que hemos decidido atender. Evidentemente, a excepción de la promoción del Perú como destino turístico, noes función del Estado, sino de las empresas turísticas 
privadas que operan en el sector.

Para terminar, si esa fue la decisión, entonces solo se tendría que poner en valor los atractivos históricos culturales de la nación, incorporándolos en la elaboración de productos turísticos que satisfagan o colmen las expectativas de nuestro nicho de mercado. Toda vez que tenemos muy claro lo que no debemos hacer. ¿ No creen que ya se hubieran puesto en valor Choquequirao, Kuelap, las tumbas reales del señor de Sipán, Chan Chan, la señora de Cao, Caral, entre otros constituyendo productos turísticos competitivos de calidad mundial?

Estas son las decisiones políticas que el país reclama, que obviamente no la pueden, ni la deben tomar los técnicos, ni los burócratas, menos los consultores, sino única y exclusivamente los líderes de los partidos políticos que están en el gobierno.

Sólo cuando éstos se pongan de acuerdo en una realidad imaginada para el turismo, es decir el tipo de país turístico que desean para las próximas generaciones y se fijen objetivos estratégicos a corto, mediano y largo plazo y se comprometan a respetarlos y hacer lo humanamente posible para hacerlo realidad, al llegar cualquiera de ellos al poder, ésta por decisión de los partidos políticos, y no por declaración romántica en un considerando de la Ley General de Turismo, se habrá elevado la política turística formulada, al nivel de política de Estado para el desarrollo del turismo nacional. Esta y no otra, es la tarea pendiente que el futuro del turismo nacional reclama a nuestra clase política.

\section{PROMOCIÓN DEL PERÚ COMO DESTINO TURÍSTICO}

Creemos que el problema radica en que no tenemos claro que la promoción de un destino turístico, como la promoción de cualquier "artículo o producto", es realizado al final de un proceso planificado de "producción" del objeto a ser comercializado (producto turístico) en el mercado, donde la promoción del mismo es una línea de acción del plan de marketing estratégico formulado para tal fin.

No debemos perder de perspectiva, que todo plan de marketing tiene como objetivo fundamental, generar los recursos económicos necesarios para financiar las actividades programadas en el plan estratégico de desarrollo de una empresa o de un destino turístico, que viabilice el logro de los objetivos estratégicos nacionales planteados en él.

Vale decir hacer realidad la visión y misión formulada por el líder de la empresa y en el caso nuestro por el líder del sector turístico nacional, o por el líder del partido político en el poder, responsable de generar la política pública para el desarrollo del turismo nacional.

Finalmente, es necesario precisar que el presupuesto para la promoción, es también una parte del presupuesto del plan de marketing. Como se podrá comprender fácilmente, no es cuestión de conocer las líneas de acción, sino el presupuesto total que nos permitirá hacer realidad los objetivos estratégicos que buscamos. En el peor de los casos, es imperativo conocer los objetivos-meta a ser alcanzados con el presupuesto asignado para las actividades de promoción a ser realizados por el país.

Sólo conociéndolos, podríamos precisar si el monto asignado a la promoción del Perú como destino turístico es adecuado o no. Creemos que una actividad aislada de su contexto y estructura, no permitirá alcanzar la máxima rentabilidad de la inversión realizada, más aún, si ésta no es evaluada a través de indicadores de proceso, resultado y eficacia.

En este contexto creemos que se lograría mayor retorno de la inversión en actividades de promoción turística si éste formara parte de la estructura de un plan de marketing estratégico para el turismo nacional, donde por un lado, estarían los objetivos-meta estratégicos de marketing a lograr (cuota de mercado a alcanzar, porcentaje de incremento anual del flujo de turistas a lograr, monto de los ingresos a incrementar, etc.) y por otro lado, estarían especificadas todas las actividades de marketing a ser desarrollados en el largo plazo (3, 5 o 10 años) y programado en los planes operativos anuales respectivos (corto plazo), especificando los montos presupuestales asignados para cada actividad programada y los resultados que se pretende logar con ellos y los 
mecanismos de monitoreo y evaluación a través de indicadores de proceso, resultado e impacto, como lo hace Españas.

Recién entonces, al haber sido costeadas todas las actividades teniendo en cuenta su costo-beneficio, costo-efectividad y costo-oportunidad, podríamos tener el monto total del presupuesto para las actividades de marketing a desarrollar anual $y$ mensualmente, que necesitaría el país para promocionarlo como destino turístico, así como para desarrollar el turismo nacional.

Como se podrá comprender es importante conocer los logros o metas que se pretende alcanzar con las actividades de promoción que se pretende realizar, toda vez que es obligación, de los funcionarios públicos, rendirle cuentas a la sociedad.Por otro lado, se ejecuta la promoción de "artículos o productos" que la plana ejecutiva o directriz ha decidido comercializar, y que fueron previamente conceptualizados, diseñados, producidos, terminados y dirigidos a un mercado objetivo definido, donde se han detectado o despertado necesidades y deseos, o descubierto nichos de mercado no acogidos o muy poco atendidos. Por lo tanto, no se nos imaginaría producir todos los "artículos o productos" que demanda un mercado, porque difícilmente podríamos producirlos todos con la misma calidad. Queremos decir, que la efectividad de las actividades de promoción depende de las decisiones estratégicas que se tuvieron que tomar antes, de tal forma que se promocione un producto de calidad superior que satisfaga las expectativas de nuestro nicho de mercado, a través de adecuados e innovadores canales de comercialización y a un precio competitivo que nuestro nicho de mercado esta dispuesto a pagar.

Condiciones, éstas, mínimas que todo Directorio exige a los ejecutivos en quienes delegaron la obligación de lograr el desarrollo sostenido de la empresa que dirigen, en el mundo globalizado altamente competitivo $y$ de cambios impredecibles donde actúan.
Si este proceder es bueno para los ejecutivos de empresas privadas, ¿por qué no exigir que lo sea también para los funcionarios (ejecutivos) del sector estatal responsable de dirigir el desarrollo del turismo nacional?

Para concluir, promocionar al Perú como destino turístico, pasa necesariamente por construir la marca país para el turismo nacional, no hacerlo implica carecer de identidad y de posicionamiento en el mercado turístico mundial.

Precisamente, creemos que el Estado debe encargarse conjuntamente de la promoción del Perú como destino turístico y del posicionamiento de la marca turística para el país al igual que su difusión. La comercialización del producto turístico es responsabilidad de las empresas turísticas que actúan en el sector, más no del Estado.

\section{POLÍTICA Y BUROCRACIA ESTATAL}

La formulación de una política turística, es una opción abstracta: implica definir el sentido que deberá tener la acción turística, conteniendo elementos normativos y prescriptivos responsables de la generación de una visión sobre un futuro imaginado que sea deseable y estimulador.

Que cada actor social del sector turismo la encuentre lleno de oportunidades para su plena realización, siendo la razón y fundamento de su compromiso de entregar lo mejor de sí para hacerlo realidad.

Es decir, interesa el encadenamiento de comportamientos intraburocráticos que traduzcan la política en acción, como la dinámica social generada por este proceso $y$ sus efectos de retroalimentación sobre el comportamiento de los actores estatales.

Todo nuevo régimen, no solo alterara la relación de fuerzas en la sociedad, sino también al interior del aparato estatal, dado que la materialización de un proyecto político exige actuar a través de una estructura burocrática preexistente, la que genera 
resistencia y suscita comportamientos que tienden a desvirtuar o atenuar el sentido de las decisiones o acciones emprendidas, ajustándose, por lo tanto, más a la racionalidad de los intereses que defienden que a la lógica de la decisión política que los afecta.

\section{POLÍTICA TURÍSTICA Y RÉGIMEN POLÍTICO}

La negociación, el ajuste mutuo y el cambio incremental son la base del estilo de decisión política en el proceso de formulación e implementación de una política publica para el turismo, la misma que es afectada, de manera diversa en su implementación, por los diferentes estilos de gestión estatal.

Los aparatos estatales altamente rutinizados y burocratizados, están regulados por una profusa legislación que trata de reducir al mínimo el ámbito de responsabilidad de cada actor a fin de evitar al máximo los posibles riesgos de la decisión tomada y mantener las formalidades existentes.

Formular los grandes lineamientos de política pública para el apoyo y promoción del turismo nacional es la tarea pendiente de los líderes de los partidos políticos vigentes en el país, para pasar del bello discurso de considerar casi unánimemente al turismo como instrumento y eje fundamental para el desarrollo del país.

Más aún, ojala tomen también la decisión postergada por lustros de reformar radicalmente el Estado para que el miedo paralizante de tomar decisiones ejecutivas en el sector estatal deje de tener vigencia en el país.

Finalmente, como expresión de la ausencia de una direccionalidad política, desprendida de una política pública para el desarrollo del turismo, la que a su vez esté inmersa como prioridad en el plan de gobierno del partido político en el poder, el PENTUR 2008- 2010, no es un plan estratégico para el desarrollo del turismo nacional, sino es un plan de desarrollo de destinos turísticos, es decir se conceptualiza que partiendo de la oferta, podemos desarrollar el turismo nacional, cuando la tendencia es enfocarse en el mercado para después generar la oferta que satisfaga las necesidades detectadas en él, o enfocarse en la competencia para realizar las mismas actividades que realizan pero de una manera diferente, o realizar actividades completamente nuevas que al interlazarlas incrementando valor en cada una de ellas, se logre establecer estrategias únicas que sean la base de nuestra diferenciación y competitividad, posibilitándonos alcanzar más rápidamente el liderazgo en el nicho de mercado seleccionado, dejando que la competencia se concentre en alcanzar la eficacia operativa.

O por último, concentrarse en nichos de mercados nuevos, desatendidos donde no tenemos que luchar por repartirnos el mismo mercado, reduciendo cada vez más nuestra cuota de participación, sino por el contrario ser los líderes en ese nicho de mercado, o en el peor de los casos, repartirnos un mercado entre menor número de competidores.

Frente a la realidad expuesta, corresponde a las universidades del país, especialmente aquellas que han asumido la responsabilidad de formar a los futuros líderes del sector turístico, que alcanzando el poder político, puedan hacer realidad el sueño acariciado por todos los que trabajamos en el turismo, de ser el destino turístico líder a nivel mundial y latinoamericano. Ojala pronto despertemos en esta bella realidad imaginada. 